\section{FROM GCSE TO T LEVEL - A NEW ROUTE INTO DENTISTRY}

A new school examination called the $\mathrm{T}$ level will be the first national education programme creating an introduction to dentistry. The course will follow GCSEs and can be taken as an alternative to A levels. It is due to be introduced in 2021 .

Completion of a $\mathrm{T}$ level will permit young people, especially those going on to an apprenticeship, to gain accredited prior learning for their study to date, providing them with an opportunity to complete their mandatory training in a quicker time.

When the time comes for T levels to be introduced, local dental committees,

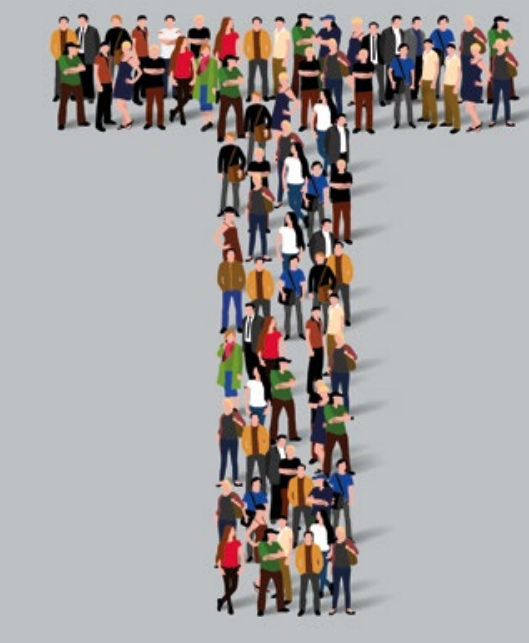

dental hospitals, large dental corporates, large dental laboratory owners and local workforce action boards are encouraged to liaise with their local education providers to ensure that the dental skill sets are not forgotten about.

For more on T levels, read Mike Wheeler's article in the June issue of BDJ Team.

\title{
DOG ATTACK SURVIVOR BECOMES SMILE AMBASSADOR
}

Tatiana Williams was mauled by a dog when she was just four years old. Three rounds of surgery and 127 stitches to her face later, she was left scarred and traumatised. Throughout her childhood she was bothered by her teeth. They drew attention to the lower part of her face - the part of her that she struggled to cope with.

But her life has been turned around by having orthodontic treatment. She was so pleased with the outcome that she entered her story into the Against the Odds award run by the British Orthodontic Society's (BOS') Orthodontic Specialists Group - and won.

Tatiana describes how and why she began treatment at the age of 24: 'Before my first consultation with Dr Adil Mannan at The Orthodontic Practice at Battersea, I was apprehensive of having to wear braces for 18-24 months. Did I really want to draw more attention to my biggest insecurity? His incredible vision and reassurance allowed me to place my trust in him and accept that this was the best thing to do. The braces were fixed and no doubt, I was more self-conscious than ever before.'

With every visit, said Tatiana, Dr Mannan's continued motivation carried her through. By the time treatment was over, she could look in the mirror and not feel disheartened by her scars.

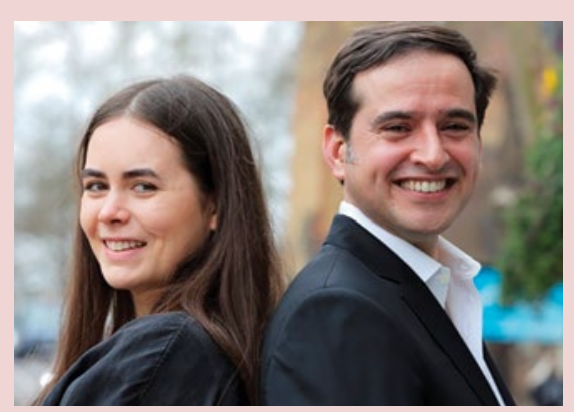

Dr Adil Mannan was delighted for Tatiana. 'I knew that orthodontics really could enhance Tatiana's life and I am so pleased to see that come to fruition. It always amazes me that someone who had such early-life trauma and has had to literally live with the scars, is so well adjusted, cheerful and full of joie de vivre.'

He added: 'I have to say that she was a fantastic patient. We talked through her understandable concerns and made sure she was involved at every stage of her treatment.'

There were two runners-up in the competition: Mr Juan Carlos Martinez from St Albans, Hertfordshire who was treated by Dr Garry Mancini of the Soho Orthodontic Clinic, London and Mr Cameron Law of Caterham, Surrey who was treated by Dr Georgina Cartwright of The Croydon Orthodontic Practice.

\section{Diany alates Jame}

\section{If you have an event you want featured in the coming year, email the Editor: k.quinlan@nature.com}

\section{British Society of Gerodontology Spring Meeting}

Date: 14 June 2019

Venue: Epsom Downs Race Course Theme: 'Making Contacts Count', oral health is the responsibility of all health care professionals and the importance of maintaining good oral health as part of the ageing process and good general health. Key speakers include Professor Martin Vernon who is talking about the long term plan and John Milne who will be sharing the soon to be released work with CQC on oral health in care homes.

Other topics include dysphagia, social prescribing, digitalisation, the role of dental care professionals and Mouth Care Matters. Suitable for: The day will be of interest to dental and non-dental care professionals at all stages of their careers.

https://www.gerodontology.com/ courses-and-events/

\section{ADAM South West Regional Cornwall Meeting \\ Date: 20 June 2019}

Venue: The Watering Hole, Perranporth Beach, Perranporth, Cornwall, TR6 0BH Cost: $£ 25$ or free for ADAM members Topics will include: Key Performance Indicators, Planning for Financial Success. 3.5 hours of CPD, refreshments included. https://bit.ly/2WLH+Kb

\section{Prescribing and interpreting radiographs for the dental hygienist and dental therapist Date: 22 June 2019 \\ Venue: JM Radiology, $37^{\text {th }}$ Floor, One Canada Square, London E14 5AA \\ Cost: $£ 200$ (50\% discount for BSDHT and BADT members). 7 hours' CPD https://www.jm-radiology.co.uk/}

